\title{
Neurotoxicity and Immunotoxicity Assessment in CBA/J Mice with Chronic Toxoplasma gondii Infection and Multiple Oral Exposures to Methylmercury
}

Author(s): Marquea D. King, David S. Lindsay, S. Holladay , and M. Ehrich

Source: Journal of Parasitology, 89(4):856-859. 2003.

Published By: American Society of Parasitologists

DOI: http://dx.doi.org/10.1645/GE-79R

URL: http://www.bioone.org/doi/full/10.1645/GE-79R

BioOne (www.bioone.org) is a nonprofit, online aggregation of core research in the biological, ecological, and environmental sciences. BioOne provides a sustainable online platform for over 170 journals and books published by nonprofit societies, associations, museums, institutions, and presses.

Your use of this PDF, the BioOne Web site, and all posted and associated content indicates your acceptance of BioOne's Terms of Use, available at www.bioone.org/page/terms_of_use.

Usage of BioOne content is strictly limited to personal, educational, and non-commercial use. Commercial inquiries or rights and permissions requests should be directed to the individual publisher as copyright holder. 


\title{
Neurotoxicity and Immunotoxicity Assessment in CBA/J Mice with Chronic Toxoplasma gondii Infection and Multiple Oral Exposures to Methylmercury
}

\author{
Marquea D. King ${ }^{\star}$, David S. Lindsay, S. Holladay, and M. Ehrich, Department of Biomedical Sciences and Pathobiology, Virginia-Maryland \\ Regional College of Veterinary Medicine, Virginia Tech, Blacksburg, Virginia 24061; *Present address: National Center for Environmental \\ Assessment, U.S. Environmental Protection Agency, 1200 Pennsylvania Avenue, NW, MC 8623-D, Washington, D.C. 20460. e-mail: \\ lindsayd@vt.edu
}

\begin{abstract}
The present study was conducted to determine the effect of multiple low doses of methylmercury $(\mathrm{MeHg})$ on the course of a chronic Toxoplasma gondii infection. Four groups of 6-wk-old female CBA/J mice either were fed $25 \mathrm{~T}$. gondii tissue cysts of the ME-49 strain or were vehicle control. Six weeks later, half of each group was orally gavaged with $8-\mathrm{mg} / \mathrm{kg}$ body weight doses of $\mathrm{MeHg}$ on days 0 , $2,4,7,10$, and 13, totaling 4 experimental groups. Mice were killed on day 17 or 18 after $\mathrm{MeHg}$ exposure. Flow cytometric analysis of lymphocyte subpopulations in the thymus demonstrated a significant increase in the percentage of $\mathrm{CD}^{-}{ }^{-} \mathrm{CD} 8^{+} \mathrm{T}$-cells in mice exposed to $\mathrm{MeHg}$ with a concurrent $T$. gondii infection. Groups of mice exposed to $\mathrm{MeHg}$ showed a decrease in total thymic cellularity and cellularity of all T-cell subpopulations when compared with control mice, but viability of these cells was unaffected. Splenic cell viability was decreased in mice exposed to $\mathrm{MeHg}$, but alterations in T-cell subpopulations were not noted. These data indicate that multiple low doses of $\mathrm{MeHg}$ may not exacerbate chronic toxoplasmosis, but MeHg-induced effects on the immune system were evident.
\end{abstract}

Toxoplasma gondii is a protozoan parasite that can cause a life-threatening disease in congenitally infected infants and immunocompromised patients. People become infected with $T$. gondii by ingesting tissue cysts in undercooked meat or by ingesting oocysts excreted by cats. Toxoplasmosis in the central nervous system is a common cause of brain lesions in acquired immune deficiency syndrome patients. In some patients suffering from toxoplasmic encephalitis, the infection may be lethal (Daubener et al., 1997; Belanger et al., 1999). Toxoplasmic encephalitis is caused by the reactivation of latent tissue cysts of $T$. gondii. Once reactivated, the tachyzoites released from tissue cysts destroy nervous tissue and cause progressive meningoencephalitis (Gazzinelli et al., 1993).

Neurotoxicants also damage nervous tissue, but few studies examining interactions of $T$. gondii and neurotoxicants have appeared in the literature (King et al., 2003). For example, methylmercury $(\mathrm{MeHg})$ is a well-documented neurotoxicant that accumulates in the brain and causes severe mental and visual dysfunction, including chronic encephalopathy (U.S. Department of Health and Human Services, 1994; Schaumburg et al., 2000). Contaminated fish, grains, and seeds are a common source of human exposure to $\mathrm{MeHg}$. In addition to being neurotoxic, $\mathrm{MeHg}$ is also immunotoxic (Moszczynski, 1997), enhancing the probability of interaction with $T$. gondii. Therefore, it was hypothesized that $\mathrm{MeHg}$ accumulation could worsen a chronic $T$. gondii infection. In the present study, multiple dosing with $\mathrm{MeHg}$ was used to provide longer exposure to this neurotoxicant than a single dose, with the potential of increasing time for a deleterious $\mathrm{MeHg}-T$. gondii interaction.

Six-week-old female CBA/J mice obtained from Jackson Laboratories (Wilmington, Massachusetts) were used for experimental $T$. gondii infection and $\mathrm{MeHg}$ exposure $(\mathrm{n}=10$ per group). These mice were used for this study because they are resistant to acute infection but are prone to develop encephalitis during a chronic infection (Suresh et al., 1991). Toxoplasma gondii dosing was as described previously (King et al., 2003). Methylmercury II chloride (Alfa Aesar, Ward Hill, Massachusetts) was dissolved in dimethyl sulfoxide (DMSO) at room temperature and diluted with phosphate buffered saline (PBS; 1:100). Oral doses of $8 \mathrm{mg} / \mathrm{kg}$ body weight were given to each mouse on days 0,2 , $4,7,10$, and 13. Vehicle controls received a DMSO-PBS suspension. The 4 experimental groups of mice used were vehicle control, $T$. gondii, $\mathrm{MeHg}$, and T. gondii-MeHg. The 8-mg/kg dosage chosen for multiple oral exposure was based on a dose response study done previously in our laboratory.

After killing by $\mathrm{CO}_{2}$ inhalation 17-18 days after the initial $\mathrm{MeHg}$ exposure, the spleen, thymus, brain, and left kidney were removed. The left half of the brain and the left kidney were used for analysis of $\mathrm{MeHg}$ concentration using a cold vapor accessory method of atomic absorption. The thymus and spleen were immediately weighed and then prepared for detection of cell surface markers using flow cytometry (King et al., 2003). These data are presented as mean \pm SE of the percentage of cells that express the surface marker of $\mathrm{CD}^{+}, \mathrm{CD}^{-} \mathrm{CD} 8^{-}$(DN, double negative), $\mathrm{CD} 4{ }^{+} \mathrm{CD} 8{ }^{+}$(DP, double positive), and $\mathrm{CD} 8+$ along with the uptake of 7-aminoactinomycin D (7-AAD), which shows apoptosis for individual phenotypes. Statistical analysis was performed using the general linear model (GLM) analysis of variance (ANOVA) from the SAS package (SAS Institute Inc., Cary, North Carolina). Significant differences among each experimental group with $P<0.05$ were reported.

Mice brains were split into right and left halves after removal. The left half was used for tissue cyst enumeration and $\mathrm{MeHg}$ quantification as described previously (Lindsay et al., 1998; King et al., 2003). Paraffin blocks were prepared from the right half of the brains, and from them separate slides were stained with hematoxylin and eosin (H\&E) and labeled with TdT-mediated deoxyuridine triphosphate (dUTP)-X nickend marker (terminal deoxynucleotidyl transferase-mediated deoxyuridine triphosphate nick-end labeling [TUNEL], Roche Molecular Biochemicals, Mannheim, Germany), and antibody to glial fibrillary acidic protein (GFAP) (Neuen-Jacob et al., 1993) was introduced, as described previously (King et al., 2003).

Mice were examined for clinical deficits indicative of neurotoxicity after $\mathrm{MeHg}$ exposure (days 0, 2, 4, 7, 10, and 13). Examinations were done during the dark cycle of the standard 12-hr light-12-hr dark cycle, using a red light lamp for observation. Behavioral response analyses were obtained and modified using an established protocol from the Laboratory for Neurotoxicity Studies at Virginia-Maryland Regional College of Veterinary Medicine (King et al., 2003), derived from original procedures for behavioral studies in rodents by Moser et al. (1988).

Body weights of the mice remained unchanged throughout dosing among all experimental groups when compared with each other or with control (group means 23-25 g). Thymus weights were decreased in the MeHg-only group $(25.4 \pm 5.2 \mathrm{mg})$ compared with controls $(43.1 \pm 4.4$ $\mathrm{mg} ; P=0.08$ ) but not in other groups. Spleen weights showed a marked increase over values from control mice $(73.2 \pm 3.4 \mathrm{mg})$ and values from mice given $T$. gondii only $(78.5 \pm 4.8 \mathrm{mg})$ in the groups exposed to $\mathrm{MeHg}(113.9 \pm 13.0 \mathrm{mg}$ in $\mathrm{MeHg}$-only mice; $P<0.05 ; 118.5 \pm$ $8.2 \mathrm{mg}$ in T.gondii-MeHg mice; $P<0.05)$. Splenic cell viability showed a significant decrease in mice infected with $T$. gondii with or without $\mathrm{MeHg}$ exposure $(P<0.05)$. Viability of cells in the thymus was unchanged (Fig. 1).

Absolute numbers of cells in the thymus of mice exposed to $\mathrm{MeHg}$ with or without a $T$. gondii infection showed a significant decrease in total numbers of $\mathrm{CD}^{+}{ }^{+} \mathrm{CD} 8{ }^{-}, \mathrm{CD} 4{ }^{-} \mathrm{CD}^{+}$, and $\mathrm{CD} 4{ }^{+} \mathrm{CD} 8{ }^{+}$T-cells $(P$ $<0.05$ ) when compared with control and $T$. gondii-infected groups (Table I). The $\mathrm{CD}^{-}{ }^{-} \mathrm{CD} 8^{-}$cell population of the thymus was also reduced, although not significantly. Each of the subpopulations of splenocytes from mice coexposed to $T$. gondii and $\mathrm{MeHg}$ was reduced, although these reductions were not statistically significant. When expressed as a percentage of total cells (Table II), flow cytometric analysis of thymocyte subpopulations of mice exposed to $\mathrm{MeHg}$ with a concurrent $T$. gondii infection showed a significant increase in the $\mathrm{CD}^{-} \mathrm{CD}^{-}$ 
Cell Viability of Thymus and Spleen in CBA/J Mice

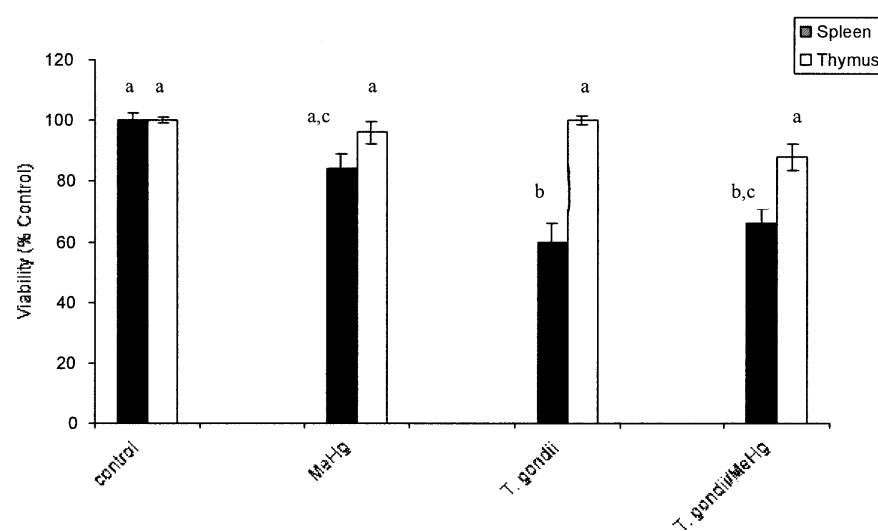

FIGURE 1. Mice dosed with $8 \mathrm{mg} / \mathrm{kg}$ body weight methylmercury ( $\mathrm{MeHg}$ ) every 2-3 days for 18 days, after a 6-wk Toxoplasma gondii chronic infection. Sacrificing was day 17 or 18 post $\mathrm{MeHg}$ exposure. Viability of cells, expressed as percentage of total cells present within the spleen and thymus, was determined by flow cytometric analysis. In the spleen, $T$. gondii decreased viability to $60 \%$ of control. Viability in spleen cells from this group of mice was also different from $\mathrm{MeHg}$ treated mice $(P<0.05)$. Decreases were seen in the spleen of mice $T$. gondii/MeHg mice. Each experimental group contained an $\mathrm{n}=10$. Comparisons among groups were performed using a Tukey's non-parametric test. For each organ no shared letters above bars implies that groups are significantly different $(P<0.05)$.

T-cell subpopulation when compared with control or $T$. gondii alone ( $P$ $<0.05$ ). Toxoplasma gondii-infected mice had a marked increase in the percentage of non- $T$ cell subpopulation and a decrease in the $\mathrm{CD} 4^{+} \mathrm{CD} 8^{-} \mathrm{T}$ cells of the spleen when compared with both control and $\mathrm{MeHg}$-exposed mice (Table II). Splenic T-cell absolute numbers showed no significant change among any of the experimental groups.

A review of $\mathrm{H} \& \mathrm{E}$-stained slides from the brains of mice that were given multiple $8-\mathrm{mg} / \mathrm{kg}$ doses of $\mathrm{MeHg}$ for 17 days did not reveal significant lesions in the brain in animals that were given $\mathrm{MeHg}, T$. gondii, or the combination of these 2 agents, or in vehicle controls. In addition, the cerebellar cortical lesions of granule cell necrosis-apoptosis (Nagashima et al., 1996) were absent in the MeHg-dosed mice regardless of the presence of a $T$. gondii infection. There were neither consistent astrocytic alterations noted in these sections using GFAP immunohistochemical staining nor any detectable apoptotic changes using the TUNEL assay on nervous or immune tissue.

Flow cytometric analysis with a triple color stain allowed for determination of apoptosis in individual T-cell subpopulations of the thymus and spleen. The only significant change in thymocytes was an increase in early apoptotic $\mathrm{CD} 4^{+} \mathrm{CD} 8^{-} \mathrm{T}$ cells in mice exposed to $T$. gondii$\mathrm{MeHg}$ (from $24.1 \pm 3.9 \%$ in controls to $42.3 \pm 5.5 \% ; P<0.05$ ). The CD4 ${ }^{-} \mathrm{CD} 8^{+}$and $\mathrm{CD} 4{ }^{+} \mathrm{CD} 8{ }^{+} \mathrm{T}$-cell subpopulations did not undergo any significant change.
Toxoplasma gondii-infected mice had more significant changes in apoptosis of spleen cells, with decreases in percentages of live $\mathrm{CD}^{+} \mathrm{CD}^{-}$and non- $\mathrm{T}$ cells and increases in late apoptotic $\mathrm{CD} 4^{+} \mathrm{CD} 8^{-}$ and $\mathrm{CD}^{-}{ }^{-} \mathrm{CD}^{+}{ }^{+} \mathrm{T}$-cell subpopulations. Not all these changes were observed in mice exposed to both $T$. gondii and $\mathrm{MeHg}$. Apoptosis staining (TUNEL) of the spleen and thymus revealed no difference between treated and nontreated groups of mice (data not shown).

Analysis for testing of repeated behavioral responses of mice exhibiting a certain response on each day was performed. Multiple-day analysis indicated that 4 of 27 responses showed a change when comparing $\mathrm{MeHg}$-only-exposed mice to $T$. gondii-MeHg-coexposed mice (click response, menace response, agility on a wooden rod, and vocalization). Of the 10 mice in each group, $70 \%, 10 \%, 70 \%$, and $40 \%$ given only $\mathrm{MeHg}$ demonstrated differences in the above-listed responses, respectively, but only on day 10 . Mice coexposed to $T$. gondii-MeHg showed signs of vocalization when handled ( 3 of the 10 mice) on day 10 . Mice infected with $T$. gondii-only or vehicle control showed no neurobehavioral abnormality before sacrifice on day 17 or 18

Although the number of tissue cysts was $3.5 \pm 1.1$ in mice exposed to $T$. gondii only and $5.6 \pm 1.1$ in mice given $T$. gondii- $\mathrm{MeHg}$, tissue cyst counts were not significantly different between the groups. Lesion scoring was similar for all groups. Coexposed mice had significantly lower brain levels of $\mathrm{MeHg}$ than the $\mathrm{MeHg}$-only-exposed mice $(0.31$ \pm 0.03 vs. $0.68 \pm 0.17 \mathrm{ppm}$, respectively). Kidney levels were $19.2 \pm$ $3.9 \mathrm{ppm}$ in mice treated with $\mathrm{MeHg}$ only and $22.1 \pm 5.2 \mathrm{ppm}$ in mice treated with $T$. gondii-MeHg. Levels of $\mathrm{MeHg}$ in mice not experimentally treated with $\mathrm{MeHg}$ were undetectable.

The present study examined the effects of multiple exposures to $\mathrm{MeHg}$ on a chronic T. gondii infection. Multiple low-dose effects in mice were less notable than when a single high dose of $\mathrm{MeHg}$ was given (King et al., 2003). For example, multiple, lower-dose exposure to $\mathrm{MeHg}$ did not increase brain tissue cysts of $T$. gondii or alter morphological effects of the infection. Because both these agents have detrimental effects on similar systems, nervous and immune (M. Aschner and J. L. Aschner, 1990; Daubener and Hadding, 1997), it was expected that the coexistence of a chronic infection and an environmental contaminant such as those examined here would worsen the initial disease state. However, the results of the present study showed that CBA/J mice demonstrated immunotoxic response to $\mathrm{MeHg}$ exposure but not a relapse of chronic toxoplasmosis.

Immune effects after multiple exposure of $\mathrm{MeHg}$ were demonstrated by a marked increase in the splenic weights of mice exposed to $\mathrm{MeHg}$ with or without a $T$. gondii infection, whereas thymus weights were decreased for the same mice. It was noteworthy that thymus weight was only different in those mice receiving multiple low doses of $\mathrm{MeHg}$ without a concurrent $T$. gondii infection. Alterations of organ weights are often primary indicators of potential immunotoxicity (Descotes, 1999). The cellularity decrease observed in the thymus of mice exposed to $\mathrm{MeHg}$ with or without a $T$. gondii infection is indicative of the depletion observed in lymphoid organs after immunosuppression. Mice coexposed to $T$. gondii and $\mathrm{MeHg}$ had a decreased splenic cellularity when compared with mice infected with only $T$. gondii in the present study. This result was different from the results of a previous study with a single high dose of $\mathrm{MeHg}$ (King et al., 2003).

The interaction of $T$. gondii and $\mathrm{MeHg}$ could be associated with effects on the immune system. Methylmercury in combination with $T$.

TABLE I. Absolute numbers of T-cell subpopulations in thymus from mice infected with Toxoplasma gondii or T. gondii and MeHg.* All data are expressed as mean $\times 10^{6}$ cells $\pm \mathrm{SE}$.

\begin{tabular}{|c|c|c|c|c|c|}
\hline Treatment & $\begin{array}{c}\text { Total } \\
\text { cellularity }\end{array}$ & \multicolumn{4}{|c|}{ Thymic T-cell subpopulation } \\
\hline Control & $86.4 \pm 8.4$ & $21.8 \pm 7.0$ & $4.1 \pm 0.5$ & $2.9 \pm 0.7$ & $57.7 \pm 4.7$ \\
\hline T. gondii & $82.5 \pm 4.9$ & $11.5 \pm 2.3$ & $4.6 \pm 0.8$ & $3.5 \pm 1.8$ & $64.7 \pm 5.9$ \\
\hline T. gondii- $\mathrm{MeHg}$ & $48.3 \pm 10.8 \dagger \ddagger$ & $6.7 \pm 2.8$ & $2.7 \pm 0.6+\neq$ & $2.0 \pm 0.7$ & $37.7 \pm 9.2 \neq$ \\
\hline
\end{tabular}

* Female CBA/J mice exposed every 2-3 days to $8 \mathrm{mg} / \mathrm{kg} \mathrm{MeHg}$ for 18 days (n = 10).

$\dagger$ Statistically significant difference $(P<0.05)$ when compared with control.

† Statistically significant difference $(P<0.05)$ when compared with $T$. gondii-infected mice. 
TABLE II. T-cell subpopulations as a percentage of total cells in the thymus and spleen of mice infected with Toxoplasma gondii or T. gondii and MeHg.* All data are expressed as percent mean \pm SE.

Percentages of T-cell subpopulations

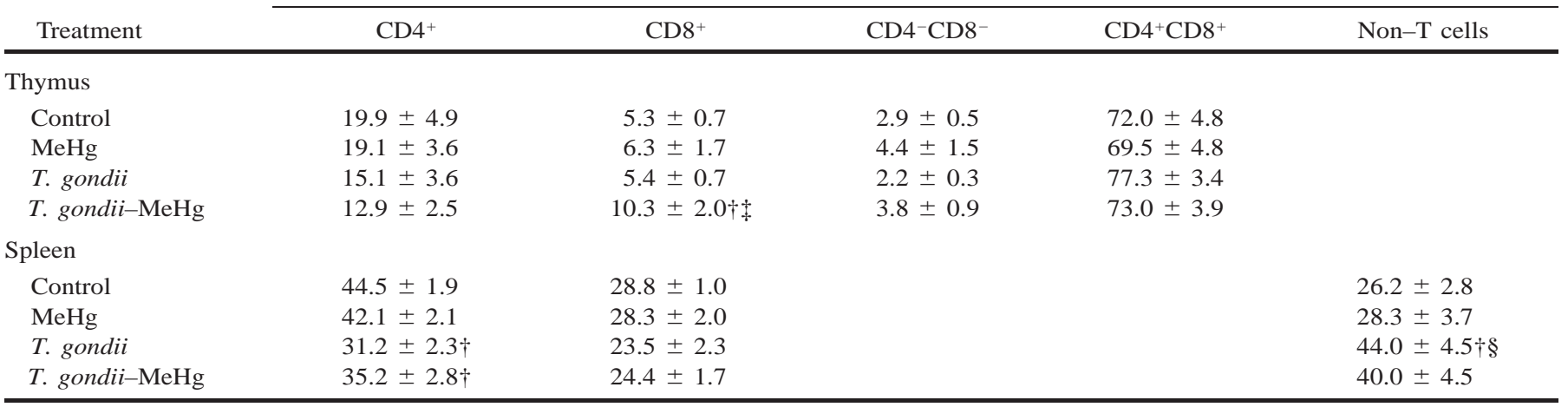

* Female CBA/J mice exposed every $2-3$ days to $8 \mathrm{mg} / \mathrm{kg} \mathrm{MeHg}$ for 18 days $(\mathrm{n}=10)$. Total cellularity of splenic cells was $52 \pm 6.5,76.9 \pm 41.7,69.0 \pm 6.3$, and

$31.6 \pm 6.0$ in control, $\mathrm{MeHg}, T$. gondii, and $T$. gondii-MeHg-treated mice, respectively.

$\dagger$ Statistically significant difference $(P<0.05)$ when compared with control.

$\dashv$ Statistically significant difference $(P<0.05)$ when compared with $T$. gondii-infected mice.

$\S$ Statistically significant difference $(P<0.05)$ when compared with $\mathrm{MeHg}$-treated mice.

gondii caused a significant increase $(P<0.05)$ in the percentage of mature $\mathrm{CD} 4{ }^{-} \mathrm{CD} 8{ }^{+} \mathrm{T}$ cells in the thymus, showing no variation in the number found in the spleen. These single positive cells are the mature $\mathrm{T}$ cells that then migrate to the periphery. These data indicate that there is either a lack of migration of $\mathrm{CD}^{-}{ }^{-} \mathrm{CD} 8^{+} \mathrm{T}$ cells or a possible increased production of these cells at this subchronic dose of $\mathrm{MeHg}$, or both. These $\mathrm{T}$ cells $\left(\mathrm{CD} 4^{-} \mathrm{CD} 8^{+}\right)$are responsible for killing cells infected by viruses, tumors, or toxicants. Other studies have found that low dosages of $\mathrm{MeHg}(10 \mathrm{ppm})$ did not affect memory of lymphocytes and that $\mathrm{T}$ rather than $\mathrm{B}$ cells are generally affected when a secondary immune response is altered after exposure to subclinical amounts of environmental contaminants (Koller et al., 1980).

Examination of mice exposed to low, multiple doses of $\mathrm{MeHg}$ for 18 days showed that mouse body weights remained unchanged throughout dosing. In experimental $\mathrm{MeHg}$ poisoning in rats and mice, the first adverse symptom noted is the loss of body weight (Suzuki and Miyama, 1971). Results obtained in the present study were not in agreement with the results of Suzuki and Miyama (1971), although our previous study with a single, higher $\mathrm{MeHg}$ dose was (King et al., 2003). The responses that indicated alterations in nervous system behavior were negligible in mice coexposed to T. gondii- $\mathrm{MeHg}$ and were noted only on day 10 after repeated exposure to $\mathrm{MeHg}$ alone. Other studies confirm the same pattern of neurological symptoms (Suzuki and Miyama, 1971). Massive doses would be expected to produce a variety of symptoms in a short time, and then the animal would die, whereas on exposure to lower doses, such as ours, the symptoms of $\mathrm{MeHg}$ poisoning are delayed (Bagenstose et al., 2001). It is possible that behavioral abnormalities could appear at time points beyond the 17 or 18 days of our experiment, but time of death was determined by the need to gather endpoints before the mice succumbed to the chronic $T$. gondii infection. This usually occurs within between 8 and 9 wk PI (Suresh et al., 1991).

Histological examination of brain tissue did not show any lesion, tissue cyst enumeration, or glial scarring that would have been indicative of $\mathrm{MeHg}$ poisoning. Again, more time may be needed before these events occur (Suzuki and Miyama, 1971). Brains of mice exposed to $\mathrm{MeHg}$ with a concurrent $T$. gondii contained less mercury than those given only MeHg. The level in the kidneys was higher than that found in the brain, indicating the animals' ability to continue to excrete mercury. In this study, the quantity of mercury in the brain $(0.68 \mathrm{ppm})$ was, however, significantly higher than the $0.35 \mathrm{ppm}$ observed 7 days after a $20-\mathrm{mg} / \mathrm{kg}$ body weight $\mathrm{MeHg}$ dose. Also notable was the difference in $\mathrm{MeHg}$ level in the brains of mice coexposed to T. gondii and $\mathrm{MeHg}$, i.e., $0.31 \mathrm{ppm}$ in the present study and $0.04 \mathrm{ppm}$ with a single $\mathrm{MeHg}$ exposure (King et al., 2003).

A plausible relationship between chronic parasitic infections and environmental contaminant exposure has not been explored previously because of the lack of relevant epidemiology studies (Clarkson et al.,
1983; Bagenstose et al., 2001). However, an earlier study in an animal model demonstrated enhanced immunotoxic effects when mice were concurrently exposed to dioxin and T. gondii (King et al., 2000). The present study is novel in that it evaluates in vivo responses of both the immune and the nervous systems after multiple exposures to a relatively low dose of an environmental contaminant that can cause neurological impairment, which has the potential to worsen over time with concurrent parasitic infections (Silbergeld et al., 2000). The results of the present study demonstrate that CBA/J mice undergo immunotoxicity because of $\mathrm{MeHg}$ exposure but not a relapse of chronic toxoplasmosis.

We thank Robert Gogal and Bernard Jortner for professional assistance with immunotoxicological and pathological studies, respectively. We are also grateful to Daniel Ward for statistical support, Joan Kalnitsky for flow cytometric analysis, and Barbara Wise for atomic absorption analysis. This work was supported by NIH Grant F36GM20301 and Virginia-Maryland Regional College of Veterinary Medicine.

\section{LITERATURE CITED}

AsCHNER, M., AND J. L. AsChNER. 1990. Mercury neurotoxicity: Mechanisms of blood-brain barrier transport. Neuroscience and Biobehavioral Reviews 14: 169-176.

Bagenstose, L. M., M. M. Mentink-Kane, A. Brittingham, D. M. Mosser, AND M. Monestier. 2001. Mercury enhances susceptibility to murine leishmaniasis. Parasite Immunology 23: 633-640.

Belanger, F., F. Derouin, L. Grangeot-Keros, and L. Meyer. 1999. Incidence and risk factors of toxoplasmosis in a cohort of human immunodeficiency virus-infected patients: 1988-1995. HEMOCO and SEROCO study groups. Clinical and Infectious Disease 28: 575-581.

Clarkson, T. W., B. Weiss, and C. Cox. 1983. Public health consequences of heavy metals in dump sites. Environmental Health Perspectives 48: 113-127.

Daubener, W., ANd U. Hadding. 1997. Cellular immune reactions directed against Toxoplasma gondii with special emphasis on the central nervous system. Medical Microbiology and Immunology 185: $195-206$.

Descotes, J. 1999. An introduction to immunotoxicology. Taylor \& Francis, Philadelphia, Pennsylvania, 183 p.

Gazzinelli, R. T., I. Eltoum, T. A. Wynn, And A. Sher. 1993. Acute cerebral toxoplasmosis is induced by in vivo neutralization of TNFalpha and correlates with the down-regulated expression of inducible nitric oxide synthase and other markers of macrophage activation. Journal of Immunology 151: 3672-3681.

King, M. D., D. S. Lindsay, M. F. Ehrich, AND M. NAGarkatti. 2000. Effect of 2,3,7,8-tetrachloro-di-benzo-p-dioxin on T cell subpopu- 
lations in the thymus and spleen of mice with chronic Toxoplasma gondii infection. International Journal of Toxicology 19: 323-329. , S. Holladay, AND M. Ehrich. 2003. Neurotoxicity and immunotoxicity assessment in $\mathrm{CBA} / \mathrm{J}$ mice with chronic Toxoplasma gondii infection and single dose exposure to methylmercury. International Journal of Toxicology 22: 1-9.

Koller, L. D., J. G. RoAn, AND J. A. Brauner. 1980. Methylmercury: Effects on B-lymphocyte receptors and phagocytosis of macrophages. Journal of Environmental Pathology and Toxicology 3: 407-411.

Lindsay, D. S., S. D. Lenz, C. C. Dykstra, B. L. Blagburn, and J. P. DUBEY. 1998. Vaccination of mice with Neospora caninum: Response to oral challenge with Toxoplasma gondii oocysts. Journal of Parasitology 84: 311-315.

Moser, V. C., J. P. McCormick, J. P. Creason, and R. C. MacPhail. 1988. Comparison of chlordimeform and carbaryl using a functional observational battery. Fundamental and Applied Toxicology 11: 189-206.

MoszCZYNSKI, P. 1997. Mercury compounds and the immune system: A review. International Journal of Occupational Medicine and Environmental Health 10: 247-258.

Nagashima, K., Y. Fuji, T. Tsukamoto, S. Nukuzuma, M. Satoh, and M. FuJitA. 1996. Apoptotic process of cerebellar degeneration in experimental methylmercury intoxication of rats. Acta Neuropathologica 91: 72-77.
Neuen-Jacob, E., C. Figge, G. Arendt, B. Wendtland, B. Jacob, and W. WeCHSLER. 1993. Neuropathological studies in the brains of AIDS patients with opportunistic diseases. International Journal of Legal Medicine 105: 339-350.

Ogata, A., J. Nishinira, T. Suzuki, K. Nagashima, and K. Tashiro. 1998. Identification of macrophage migration inhibitory factor mRNA expression in neural cells of the rat brain by in situ hybridization. Neuroscience Letters 246: 173-177.

Schaumburg, H. H., AND P. S. SPENCER. 2000. Classification of neurotoxic responses based on vulnerability of cellular sites. Neurological and Clinical 18: 517-524.

Silbergeld, E. K., J. B. SACCi, And A. F. Azad. 2000. Mercury exposure and murine response to Plasmodium yoelii infection and immunization. Immunopharmacology and Immunotoxicology 22: 685-695.

SuRESH, K., J. W. MAK, AND H. S. YoNG. 1991. Immune response in acute Toxoplasma infection of $\mathrm{Balb} / \mathrm{C}$, ICR and $\mathrm{CBA} / \mathrm{J}$ mice. Southeast Asian Journal of Tropical Medicine and Public Health 22: $452-454$.

SuZUKI, T., AND T. MiYAMA. 1971. Neurological symptoms and mercury concentration in the brain of mice fed with methylmercury salt. Industrial Health 9: 51-58.

U.S. Department of Health and Human Services. 1994. Toxicological profile for mercury (update). Agency for Toxic Substances and Disease Registry, Atlanta, Georgia, 617 p.

\title{
Meningoencephalitis Associated with an Unidentified Apicomplexan Protozoan in a Pacific Harbor Seal
}

\author{
J. M. Lapointe*, P. J. Duignan†, B. C. Barrł, A. K. Petrich§, D. W. MacPherson\|, F. M. Gulland\#, and J. P. Dubeyף, University of \\ California-Davis, Davis, California 95616; *Present address: 393 Pequot Avenue, New London, Connecticut 06320; †Institute of Veterinary, \\ Animal, and Biomedical Sciences, Massey University, New Zealand; ‡California Animal Health and Food Safety Laboratory System, Davis, \\ California 95616; \$Microbiology Department, St. Joseph's Healthcare, Hamilton, Ontario, Canada L8N 4A6; |Centre for Emergency \\ Preparedness and Response, Health Canada, Ottawa, Ontario, Canada K1A OK9; \#The Marine Mammal Center, Marin Headlands, Sausalito, \\ California 94965; ПParasite Biology, Epidemiology, and Systematics Laboratory, USDA-ARS, Beltsville, Maryland 20705. e-mail: jean- \\ martin_lapointe@groton.pfizer.com
}

ABSTRACT: A Pacific harbor seal (Phoca vitulina richardsii) was found on the central California coast with neurologic signs and labored breathing, which were unresponsive to treatment. Necropsy revealed a nonsuppurative necrotizing meningoencephalitis, a multilocular thymic cyst, and nonsuppurative cystitis and renal pyelitis. Microscopic examination revealed protozoans in the brain, thymic cyst, and bladder mucosa. Ultrastructurally, the protozoal tachyzoites were different from those of Neospora caninum, Toxoplasma gondii, and Sarcocystis neurona; the rhoptries were small and had electron-dense contents, and the organism divided by endodyogeny. Specific antibodies were not detected in serum using agglutination ( $N$. caninum, $T$. gondii) and immunoblot assays ( $S$. neurona). Immunohistochemistry for these organisms was negative. Polymerase chain reaction on brain tissue using specific primers did not amplify $T$. gondii deoxyribonucleic acid. The meningoencephalitis in this seal thus appears to have been caused by a novel protozoan.

Infections of wild mammals by apicomplexan protozoans, including Toxoplasma gondii, Neospora caninum, and Sarcocystis neurona, have been reported regularly over the past 20 yr. Several pinniped species have been found to be susceptible to $T$. gondii or $S$. neurona, including harbor seals (Phoca vitulina richardsii) (Van Pelt and Dietrich, 1973; Lapointe et al., 1998), northern fur seals (Callorhinus ursinus) (Holshuh et al., 1985), and sea otters (Enhydra lutris) (Lindsay et al., 2001). The target organs vary, but the central nervous system is often severely affected. Simultaneous infections by $T$. gondii and $S$. neurona have also been observed (Lindsay et al., 2001; Miller et al., 2001). The present report describes a harbor seal with meningoencephalitis associated with an apicomplexan protozoan different from $T$. gondii, $N$. caninum, and S. neurona.

In June 1994, a juvenile female Pacific harbor seal was found alive but weak on the seashore near Bolinas, Marin County, California, and was brought to the Marine Mammal Center in Sausalito, California. It was $74 \mathrm{~cm}$ in length and weighed $21.6 \mathrm{~kg}$; the umbilical stump was not visible. On the basis of appearance and stranding location, its age was estimated at 2-4 wk. It was given supportive treatment for 5 days, including nasogastric intubation and feeding, but on the last day its breathing was labored and it had dilated pupils and suffered seizures. It was given $0.5 \mathrm{mg}$ of diazepam intravenously (i.v.) and $20 \mathrm{mg}$ dexamethasone i.v. but remained unresponsive and was killed shortly thereafter with $3 \mathrm{ml}$ pentobarbital i.v.

On necropsy, a $10-\mathrm{cm}$ diameter mass was found within the cranial mediastinum, containing multiple cystic cavities filled with purulent exudate. The cerebral cortex appeared swollen, pale, and edematous.

For histology, sections of brain, spinal cord, mediastinal mass, liver, lung, kidney, bladder, heart, spleen, stomach, intestine, lymph nodes, adrenals, and pancreas were fixed in $10 \%$ buffered formalin and were embedded in paraffin; $5-\mu \mathrm{m}$ sections were stained with hematoxylineosin (HE) and examined using light microscopy.

Sections of cerebral cortex were also examined using transmission electron microscopy. Formalin-fixed tissue was postfixed in $1 \%$ osmium tetroxide, dehydrated through graded alcohols and propylene oxide, and embedded in epon-araldite resin. Sections 600 to 900 A thick were stained with uranyl acetate-lead citrate and examined with a transmission electron microscope at $80 \mathrm{kV}$. 